\title{
Associations between Hours Worked, Symptoms and Health Resource Utilization among Full-time Male Japanese Workers
}

\author{
Keiko Sato ${ }^{1}$, Shin Yamazaki $^{1}$, Yasuaki Hayashino ${ }^{1}$, Misa Takegami ${ }^{1}$, Yasuharu Tokuda ${ }^{2}$, \\ Osamu Takahashi ${ }^{3}$, Takuro Shimbo ${ }^{4}$, Shigeaki HinOHARA ${ }^{3}$, Tsuguya FukuI ${ }^{3}$ and \\ Shunichi FUKUHARA ${ }^{1}$
}

${ }^{1}$ Department of Epidemiology and Health Care Research, Graduate School of Medicine and Public Health, Kyoto University, ${ }^{2}$ Tsukuba University Hospital Mito Medical Center, ${ }^{3}$ Center for Clinical Epidemiology, St. Luke's Life Science Institute, St. Luke's International Hospital and ${ }^{4}$ Research Institute, International Medical Center of Japan, Japan

\begin{abstract}
Associations between Hours Worked, Symptoms and Health Resource Utilization among Full-time Male Japanese Workers: Keiko Sato, et al. Department of Epidemiology and Health Care Research, Graduate School of Medicine and Public Health, Kyoto University-Objectives: To investigate the association between hours worked, symptoms experienced, and health resource utilization. Methods: Data were collected from a nationally representative sample of households in Japan. We studied full-time male workers aged 18-65 yr who worked $100 \mathrm{~h}$ or more per month. First, we examined the association between hours worked and symptoms experienced. Second, we examined the association between hours worked and the type of health resource utilized, such as physician visits, over-the-counter (OTC) medication use, dietary supplement use, and complementary and alternative medicine (CAM) provider visits. We used a multivariable negative binominal model in each analysis. Results: Of the 762 male workers, 598 reported experiencing symptoms at least once a month. We categorized participants based on the number of hours worked per month (h/mo): 100-200 h/mo, 201-250 h/mo, and over $250 \mathrm{~h} / \mathrm{mo}$. Compared with those working 201-250 h/ mo, those working 100-200 h/mo had more frequent physician visits (rate ratio:1.67, $95 \% \mathrm{Cl}: 1.17$ to 2.38 ) and those working over $250 \mathrm{~h} / \mathrm{mo}$ had significantly lower rates of CAM provider visits and tended to use dietary supplements for symptoms. Participants who worked 201-250 h/mo used OTC medication most frequently.
\end{abstract}

Received Nov 19, 2010; Accepted Mar 15, 2011

Published online in J-STAGE Apr 14, 2011

Correspondence to: S. Fukuhara, Department of Epidemiology and Health Care Research, Graduate School of Medicine and Public Health, Kyoto University, Yoshida Konoe-cho, Sakyo-ku, Kyoto 606-8501, Japan (e-mail: s.fukuhara@at3.ecs.kyoto-u.ac.jp)
No significant association was observed between the number of hours worked and number of symptoms experienced. Conclusions: The more hours worked by full-time male workers, the more likely they were to use health resources that had a lower time requirement. Greater attention should be paid to patterns of health resource utilization among workers and their consequent influence on long-term health status.

(J Occup Health 2011; 53: 197-204)

Key words: Health services accessibility, Occupational health, Signs and symptoms

The number of work compensation claims relating to cerebrovascular disease and cardiovascular disease has been increasing in Japan, with almost 900 cases recorded in $2008^{1)}$.

Among these, more than 300 deaths were considered to be directly associated with excessive working hours. By age, the incidence of death from overwork tends to be highest among people in their fifties, whereas overworkassociated mental disorders tend to be highest in people in their thirties. According to the International Labour Organization database ${ }^{2)}$, Japanese employees work longer hours [42.4 h per week (h/wk)] than those of other countries (i.e. United States; $40.8 \mathrm{~h} / \mathrm{wk}$; Germany; $28.4 \mathrm{~h} /$ wk; United Kingdom, 37.7 h/wk). The association between working hours and health remains a pressing issue, especially in middle-aged male workers ${ }^{3)}$. Although studies have reported an association between long working hours and diseases such as hypertension ${ }^{4,5)}$, diabetes ${ }^{6}$, myocardial infarction ${ }^{7}$, back pain $^{8)}$, cognitive function ${ }^{9)}$ and depression ${ }^{10)}$, research in this area has failed to provide clear results directly linking working hours with morbidity and health. 
Various mechanisms to explain how long working hours may affect health have been suggested ${ }^{11-13)}$. First, long working hours reduce the amount of time for sleep, and lack of sleep in turn results in insufficient recovery from fatigue. This may affect physiological processes such as regulation of blood pressure, hormone excretion, and sympathetic nervous system activity and subsequently result in psychological and physical health complaints. Second, long working hours may be associated with unhealthy lifestyle factors such as smoking, unhealthy diet, excessive alcohol consumption and a sedentary lifestyle ${ }^{11)}$. In turn, unhealthy lifestyle factors lead to physiological changes (e.g., hypertension, hypercholesterolemia) and an increased risk of cardiovascular disease and other adverse health outcomes.

Even though associations between long working hours and various diseases have been reported ${ }^{4-16)}$, few studies have examined whether the number of hours worked influences health resource utilization among symptomatic workers. Here, we assumed that symptomatic workers have various options, such as visiting a physician, use of over-the-counter (OTC) medication or dietary supplements or visiting a complementary and alternative medicines (CAM) provider. The aims of this study were to examine the association between hours worked and symptoms experienced among full-time male workers and between hours worked and the type of health resources utilized.

\section{Methods}

\section{Study design and setting}

Data were obtained from a prospective cohort study using participants' health diaries established for ecological analysis of medical care in Japan ${ }^{17}$. Briefly, a populationweighted random sample of households was selected by controlling for the size of cities, towns and villages from a nationally representative panel comprising 210,000 households maintained by Japan Statistics \& Research Co. Ltd. A random sample of 5,387 households was chosen, each of which received a letter describing the study and requesting participation. Of these, 1,857 households initially agreed to participate. The sample size was readjusted to 1,464 households to make it nationally representative. Baseline questionnaires were mailed to 3,852 individuals in these households, of whom 3,477 from 1,286 households completed the questionnaire and were subsequently sent the health diary. After excluding individuals aged less than $18 \mathrm{yr}, 2,371$ individuals, including 1,065 men, completed the health diary. Participants were asked to personally fill out the baseline questionnaire from September 18, 2003 until October 3, 2003 and the health diary from October 1, 2003 until October 31, 2003.

\section{Study population, questionnaire and health diary}

Given the Japanese retirement-age system, participants between 18 and $65 \mathrm{yr}$ old were included in the analysis. Individuals who were hospitalized during the period in which the health diary was completed or who did not complete questions regarding the number of hours worked were excluded from the analysis. Individuals who worked less than $100 \mathrm{~h}$ per month were also excluded as it was considered more likely that they had serious health conditions. The baseline questionnaire included questions covering hours worked per day, working days per month, age, sex, height, weight, area of residence, cohabitation with a family member, current health status, annual household income, employment status, occupation and the SF-8 Health Survey (SF-8). The health diary asked participants about symptoms they may have experienced and how they dealt with these symptoms. The questions were: Did you have any pain or other symptoms that made you uncomfortable today? If so, please write down the specific symptoms. If you did experience symptoms, did you (1) take over-the-counter (OTC) medication, (2) take dietary supplements (e.g. vitamins, calcium preparations), (3) visit a complementary and alternative medicines (CAM) provider, such as one providing acupressure, acupuncture or massage, (4) consult a physician or (5) visit a hospital emergency room.

\section{Hours worked, symptoms experienced and health resource utilization}

We divided hours worked per month into three groups: (1) short work group, 100 to $200 \mathrm{~h}$ per month; (2) reference group, 201 to $250 \mathrm{~h}$ per month; and (3) long work group, above $250 \mathrm{~h}$ per month. We assessed symptoms experienced by calculating the number of pains or symptoms recorded in the health diary, and assessed health resource utilization by calculating the number of physician or emergency room visits, and instances of OTC medication, dietary supplementation and CAM provider visits. Participants who were not experiencing any symptoms did not answer the questions regarding health resource utilization.

\section{Covariates}

As there was no linear association between age and the occurrence of symptoms, age was divided into three categories: (1) 18 through $29 \mathrm{yr}$, (2) 30 through $49 \mathrm{yr}$ and (3) 50 through $65 \mathrm{yr}$. Area of residence was divided into two categories according to population: (1) less than 100,000 , and (2) 100,000 people or more. Based on the average (6.00 million yen) and median (4.76 million yen) household income for Japan in 2002, annual household income was divided into three categories: (1) less than 3.00 million yen per year, (2) 3.00 to 6.99 million yen per year and (3) 7.00 million yen per year and above. Occupation was categorized as (1) employee and 
nonmanager, (2) employee and manager, and (3) employer or professional/board member/ proprietor. Body Mass Index (BMI) was divided into three categories: (1) less than $18.5 \mathrm{~kg} / \mathrm{m}^{2}$, (2) $18.5-25 \mathrm{~kg} / \mathrm{m}^{2}$ and (3) over $25 \mathrm{~kg} / \mathrm{m}^{2}$.

The SF-8 Health Survey (Medical Outcomes Trust, Waltham, MA, USA) was used to measure health-related quality of life $(\mathrm{QOL})^{18)}$. The SF-8 generates a health profile consisting of eight scales and two summary measures, a physical component summary (PCS) and a mental component summary (MCS). A higher or lower individual score indicates a better or worse health status than the mean, respectively ${ }^{18)}$. We included PCS and MCS scores as continuous variables and divided the number of diseases currently being treated into three categorical variables: (1) none, (2) one and (3) two or more. The number of symptoms reported in the health diary was divided three categories: (1) one to four, (2) five to nine and (3) more than ten.

\section{Statistical methods}

First, the association between hours worked and symptoms experienced was calculated by rate ratio (RR) and $95 \%$ confidence interval (CI) among all participants using the negative binominal regression model. It appropriates Poisson regression but is more appropriate when overdispersion occurs when the variance is greater than the mean and when the independence assumption may be violated ${ }^{19)}$. We determined the adjusted RR (ARR) by controlling for age, area of residence, cohabitation with a family member, annual household income, occupation, number of diseases currently being treated, SF-8 PCS and MCS score and BMI. When an individual recorded more than one symptom on the same day, we included all symptoms in the calculation. Second, we used the multivariable negative binominal regression model to determine the association between hours worked and the type of health resource utilized among those who reported symptoms at least once in the health diary for that day. When an individual used multiple health resources on the same day, we included all of them in the calculation. In the second analysis, we determined ARR controlled for age, area of residence, cohabitation with a family member, annual household income, occupation and number of symptoms per month. Data preparation and analysis were conducted using the SAS version 9.1 software (SAS Institute, Inc., Cary NC, USA), and a two-tailed $p$-value of 0.05 was regarded as statistically significant.

\section{Results}

Among 1,065 male participants, 810 reported being fulltime workers. Individuals aged over $65 \mathrm{yr}(\mathrm{N}=20)$, those who worked less than $100 \mathrm{~h}$ per month $(\mathrm{N}=14)$, those who did not complete the questions regarding the number of hours worked $(\mathrm{N}=9)$ or those who were hospitalized during the study period $(\mathrm{N}=5)$ were excluded, leaving 762 men available for analysis. Table 1 shows the characteristics of the participants according to hours worked per month.

The mean number of hours worked was $228.3 \mathrm{~h}$ [standard deviation (SD) $61.8 \mathrm{~h}$, range 100-398 h], and the median was $216.0 \mathrm{~h}$ for all participants. There were 82 individuals (11\%) who worked more than $300 \mathrm{~h}$ per month.

\section{Symptoms experienced}

Among the 762 participants, 598 individuals (78.5\%) reported symptoms at least once, and a total of 122 types of symptoms were reported during the month in which the health diary was completed. The mean number of times per month symptoms were experienced was 8.41 (SD 11.4; Table 1). Table 2 shows the symptoms that were reported by more than $10 \%$ of participants.

\section{Health resource utilization}

Table 3 shows the number of health resources utilized during the month in which the health diary was completed. In each working hour group, OTC medication was the most frequently used health resource. Participants in the long work group utilized access to a physician, CAM provider and OTC medications the least frequently and dietary supplements and emergency room visits the most frequently.

\section{Association between hours worked and symptoms experienced}

Table 4 shows the association between hours worked and symptoms experienced. There was no significant difference in ARRs between the reference group and the short or long work groups.

\section{Association between hours worked and the type of health resource utilized}

Table 5 shows crude and adjusted RRs between working hours and health resource utilization. The ARR for physician visits, OTC medication use and dietary supplement use differed significantly for the short and long work groups when compared with the reference group. Specifically, participants in the short work group visited a physician significantly more often than individuals in the reference group [ARR=1.77 (95\% CI: 1.09 to 2.87)], while there was no significant difference between the reference and long work groups. Participants in the long work group visited a CAM provider less often than individuals in the reference group, although the difference was not significant. Compared with the reference group, OTC medication use was significantly lower in both the short and long work groups [ARR $=0.75$ (95\% CI: 0.57 to 0.97), ARR=0.73 (95\% CI: 0.55 to 0.96), respectively], indicating that the reference group showed a significant 
Table 1. Demographic and socioeconomic characteristics of the participants*

\begin{tabular}{|c|c|c|c|c|c|c|c|c|}
\hline \multirow[b]{3}{*}{ Characteristic } & \multirow{2}{*}{\multicolumn{2}{|c|}{$\begin{array}{c}\text { All } \\
\text { participants } \\
(\mathrm{n}=762)\end{array}$}} & \multicolumn{6}{|c|}{ Hours worked/mo } \\
\hline & & & \multicolumn{2}{|c|}{$\begin{array}{l}100-200 \\
(\mathrm{n}=331)\end{array}$} & \multicolumn{2}{|c|}{$\begin{array}{l}201-250 \\
(n=213)\end{array}$} & \multicolumn{2}{|c|}{$\begin{array}{c}251+ \\
(n=218)\end{array}$} \\
\hline & $\mathrm{n}$ & (\%) & $\mathrm{n}$ & $(\%)$ & & $\%)$ & $\mathrm{n}$ & $(\%)$ \\
\hline \multicolumn{9}{|l|}{ Age (yrs) } \\
\hline $18-29$ & 112 & $(15)$ & 43 & (13) & 32 & (15) & 37 & $(17)$ \\
\hline $30-49$ & 482 & $(63)$ & 180 & $(54)$ & 145 & $(68)$ & 157 & $(72)$ \\
\hline $50-65$ & 168 & (22) & 108 & (33) & 36 & (17) & 24 & (11) \\
\hline \multicolumn{9}{|l|}{ Population of area of residence } \\
\hline$\geq 100,000$ & 311 & $(41)$ & 134 & $(40)$ & 98 & (46) & 79 & (36) \\
\hline$<100,000$, Rural area & 451 & $(59)$ & 197 & $(60)$ & 115 & $(54)$ & 139 & $(64)$ \\
\hline \multicolumn{9}{|l|}{ Cohabitation with family } \\
\hline Living alone & 259 & (34) & 106 & (32) & 76 & (36) & 77 & $(35)$ \\
\hline Other & 503 & $(66)$ & 225 & (68) & 137 & $(64)$ & 141 & $(65)$ \\
\hline \multicolumn{9}{|l|}{ Occupation } \\
\hline Employee & 485 & (64) & 221 & (67) & 130 & $(61)$ & 134 & $(61)$ \\
\hline Employee, manager & 179 & (23) & 73 & (22) & 56 & (26) & 50 & (23) \\
\hline Employer, specialist & 91 & (12) & 33 & (10) & 25 & (12) & 33 & (15) \\
\hline \multicolumn{9}{|c|}{ Annual household income (million yen) } \\
\hline$<3.00$ & 58 & (8) & 17 & $(5)$ & 21 & $(10)$ & 20 & (9) \\
\hline $3.00-6.99$ & 419 & $(55)$ & 164 & $(50)$ & 128 & $(60)$ & 127 & $(58)$ \\
\hline$\geq 7.00$ & 278 & $(36)$ & 146 & (44) & 62 & (29) & 70 & $(32)$ \\
\hline \multicolumn{9}{|l|}{ QOL score } \\
\hline PCS score (Mean, SD) & 50.1 & $(6.1)$ & 50.3 & $(6.1)$ & 50.0 & $(6.4)$ & 49.9 & $(5.9)$ \\
\hline MCS score (Mean, SD) & 47.9 & $(6.7)$ & 48.5 & (6.4) & 48.0 & $(6.8)$ & 47.0 & $(7.0)$ \\
\hline \multicolumn{9}{|l|}{ BMI $\left(\mathrm{kg} / \mathrm{m}^{2}\right)$} \\
\hline$<18.5$ & 32 & (4) & 12 & (4) & 10 & $(5)$ & 10 & (5) \\
\hline $18.5-25.0$ & 552 & $(72)$ & 241 & (73) & 158 & (74) & 153 & $(70)$ \\
\hline$>25.0$ & 178 & (23) & 78 & (24) & 45 & $(21)$ & 55 & $(25)$ \\
\hline \multicolumn{9}{|l|}{ Number of diseases under treatment } \\
\hline None & 600 & $(79)$ & 253 & (76) & 169 & (79) & 178 & $(82)$ \\
\hline One & 126 & (17) & 60 & (18) & 33 & (15) & 33 & $(15)$ \\
\hline Two or more & 36 & $(5)$ & 18 & $(5)$ & 11 & $(5)$ & 7 & (3) \\
\hline $\begin{array}{l}\text { Number of symptoms per month } \\
\text { (Mean, SD) }\end{array}$ & 8.41 & $(11.4)$ & 8.25 & $(10.7)$ & 8.24 & $(12.7)$ & 8.82 & (11.1) \\
\hline
\end{tabular}

(762 participants, full-time male Japanese workers, 2003)

*QOL, quality of Life; PCS, physical component summary; MCS, mental component summary; BMI, Body Mass Index; and SD, standard deviation.

positive rate ratio for OTC use.

Dietary supplement use in the long work group was significantly higher than the reference group [ARR=3.48 (95\% CI: 1.41 to 8.57)]. Among a total of six participants who reported visiting an emergency room, four were from the long work group, and one each was from the reference and short work groups (Table 3). In summary, the short work group showed the highest positive rate ratio for physician visits, the reference group showed the highest positive rate ratio for OTC use and the long work group showed the highest positive rate ratio for dietary supplement use.

\section{Discussion}

To our knowledge, this is the first study to investigate the association between hours worked and the utilization of various health resources, namely physician or emergency room visits, OTC medication, dietary supplements and CAM provider visits. Here, we showed that there are numerous associations between the number of hours worked and the type of health resource utilized by full-time male workers. For example, we found that OTC medication was the most frequent health resource utilized for symptoms experienced by the participants in this study. We also found that participants who worked 
Table 2. Symptoms reported in the health diary

\begin{tabular}{|c|c|c|c|c|}
\hline \multirow[b]{3}{*}{ Symptom } & \multirow{2}{*}{$\begin{array}{c}\text { All } \\
\text { participants } \\
(\mathrm{n}=762) \\
\end{array}$} & \multicolumn{3}{|c|}{ Hours worked/mo } \\
\hline & & $\begin{array}{l}100-200 \\
(n=331)\end{array}$ & $\begin{array}{l}201-250 \\
(n=213)\end{array}$ & $\begin{array}{c}251+ \\
(\mathrm{n}=218)\end{array}$ \\
\hline & n $(\%)$ & $\mathrm{n} \quad(\%)$ & $\mathrm{n}(\%)$ & $\mathrm{n}(\%)$ \\
\hline Lower back pain/complaints & $167 \quad(22)$ & $79 \quad(25)$ & $54(25)$ & $34(16)$ \\
\hline Headache & 157 (21) & $61 \quad(19)$ & 37 (17) & $59(27)$ \\
\hline Weakness/fatigue & 138 (18) & $48 \quad(15)$ & $33(15)$ & $57(26)$ \\
\hline Neck pain/complaints & 112 (15) & $40 \quad(13)$ & $33(15)$ & $39(18)$ \\
\hline Sneezing/nasal obstruction & 110 (14) & $52(17)$ & $21(10)$ & $37(17)$ \\
\hline Throat pain/complaints & $106(14)$ & 45 (14) & $25(12)$ & $36(17)$ \\
\hline Cough & $93(12)$ & 42 (13) & $22(10)$ & $29(13)$ \\
\hline Acute upper respiratory inflammation & 73 (10) & $28 \quad(9)$ & $22(10)$ & $23(11)$ \\
\hline
\end{tabular}

(762 participants, full-time male Japanese workers, 2003)

Table 3. Types of health resources utilized per month*

\begin{tabular}{|c|c|c|c|c|}
\hline \multirow[b]{3}{*}{$\begin{array}{l}\text { Type of health } \\
\text { resource }\end{array}$} & \multicolumn{4}{|c|}{ Mean number of health resources utilized/month (SD) } \\
\hline & \multirow{2}{*}{$\begin{array}{l}\text { Participants who } \\
\text { reported symptoms } \\
\qquad(\mathrm{n}=598)\end{array}$} & \multicolumn{3}{|c|}{ Hours worked/mo } \\
\hline & & $\begin{array}{l}100-200 \\
(n=257)\end{array}$ & $\begin{array}{c}201-250 \\
(n=160)\end{array}$ & $\begin{array}{c}251+ \\
(n=181)\end{array}$ \\
\hline Physician visits & $0.44(1.35)$ & 0.59 & $0.38 \quad(1.67)$ & $0.28(0.82)$ \\
\hline CAM provider visits & $0.14(1.03)$ & $0.16 \quad(0.92)$ & $0.13(0.60)$ & $0.13(1.42)$ \\
\hline OTC medication use & $3.01(4.53)$ & 2.84 & $3.73 \quad(5.34)$ & $2.63(4.34)$ \\
\hline Dietary supplement use & $1.24(4.62)$ & 1.15 & $1.13(4.94)$ & $1.45(4.61)$ \\
\hline Emergency room visits & $6(1.0)$ & $1(0.3)$ & $1(0.4)$ & $4(1.3)$ \\
\hline
\end{tabular}

(762 participants, Japanese full-time workers, 2003)

* SD, standard deviation; CI, confidence interval; OTC, over the counter; CAM, complementary and alternative medicine.

$\dagger$ Emergency room visits are shown as the number of visits and percentage.

Table 4. Rate ratios and $95 \%$ confidence intervals for associations between hours worked and symptoms experienced*

\begin{tabular}{|c|c|c|c|c|c|c|}
\hline \multirow[b]{2}{*}{ Hours worked/mo } & \multicolumn{3}{|c|}{ Crude } & \multicolumn{3}{|c|}{ Adjusted $\dagger$} \\
\hline & $\mathrm{RR}$ & $(95 \% \mathrm{CI})$ & $p$-value & $\mathrm{RR}$ & $(95 \% \mathrm{CI})$ & $p$-value \\
\hline $100-200$ & 1.00 & $(0.79-1.26)$ & 0.988 & 1.05 & $(0.83-1.33)$ & 0.714 \\
\hline $201-250$ & (ref) & & & (ref) & & \\
\hline $251+$ & 1.07 & $(0.83-1.38)$ & 0.602 & 1.15 & $(0.89-1.48)$ & 0.280 \\
\hline
\end{tabular}

(762 participants, full-time male Japanese workers, 2003)

* RR, rate ratio; and CI, confidence interval. †Adjusted by negative binominal regression for age, area of residence, cohabitation with family, occupation, annual household income, number of diseases being treated, quality of life scores at baseline and Body Mass Index.

100 to $200 \mathrm{~h}$ per month had significantly higher rates of physician visits than those who worked more than 200 hours per month. Further, participants who worked 201 to $250 \mathrm{~h}$ per month had significantly higher rates of OTC medication use than those who work shorter or longer hours. Moreover, participants who worked more than 250 $\mathrm{h}$ per month had significantly higher rates of dietary supplement use and visited emergency rooms more often than those who work $250 \mathrm{~h}$ or less per month.

Association between hours worked and health resource utilization

For full-time male workers who experienced symptoms, the number of hours worked influenced the health resource they utilized. We speculated that an increase in the number of hours worked may act as a barrier ${ }^{20)}$ to accessing certain 
Table 5. Rate ratios and $95 \%$ confidence intervals for associations between hours worked and health resource utilization*

\begin{tabular}{|c|c|c|c|c|c|c|c|c|c|c|c|c|}
\hline \multirow{3}{*}{$\begin{array}{l}\text { Hours } \\
\text { worked /mo }\end{array}$} & \multicolumn{12}{|c|}{ Health resource } \\
\hline & \multicolumn{3}{|c|}{ Physician visits } & \multicolumn{3}{|c|}{ CAM provider visits } & \multicolumn{3}{|c|}{ OTC medication use } & \multicolumn{3}{|c|}{ Dietary supplement use } \\
\hline & $\mathrm{RR}$ & $(95 \% \mathrm{CI})$ & $p$-value & $\mathrm{RR}$ & $(95 \% \mathrm{CI})$ & $p$-value & $\mathrm{RR}$ & $(95 \% \mathrm{CI})$ & $p$-value & $\mathrm{RR}$ & $(95 \% \mathrm{CI})$ & $p$-value \\
\hline \multicolumn{13}{|l|}{ Crude } \\
\hline $100-200$ & 1.54 & ( 0.95 to 2.52 & 0.084 & 1.25 & (0.36 to 4.31$)$ & 0.729 & 0.76 & (0.57 to 1.02$)$ & 0.070 & 1.02 & (0.47 to 2.25$)$ & 0.954 \\
\hline $201-250$ & (ref) & & & (ref) & & & (ref) & & & (ref) & & \\
\hline $251+$ & 0.74 & ( 0.42 to 1.30 & 0.291 & 1.06 & $(0.28$ to 4.07$)$ & 0.932 & 0.71 & (0.51 to 0.97$)$ & 0.033 & 1.29 & (0.55 to 3.02$)$ & 0.544 \\
\hline \multicolumn{13}{|l|}{ Adjusted $\dagger$} \\
\hline $100-200$ & 1.77 & (1.09 to 2.87 & ) 0.021 & 0.97 & (0.30 to 3.17$)$ & 0.959 & 0.75 & (0.58 to 0.97$)$ & 0.029 & 1.35 & (0.55 to 3.30$)$ & 0.516 \\
\hline $201-250$ & (ref) & & & (ref) & & & (ref) & & & (ref) & & \\
\hline $251+$ & 1.11 & (0.64 to 1.93 & 0.720 & 0.46 & (0.11 to 1.89$)$ & 0.281 & 0.73 & (0.55 to 0.96$)$ & 0.022 & 3.48 & (1.41 to 8.57$)$ & 0.007 \\
\hline
\end{tabular}

(598 participants who had one or more symptoms per month, full-time male Japanese workers, 2003)

$*$ RR, rate ratio; CI, confidence interval; OTC, over the counter; and CAM, complementary and alternative medicine. $\dagger$ Adjusted for age, area of residence, cohabitation with family, occupation, annual household income, and number of symptoms per month by negative binominal regression.

health resources and that certain resources would be preferred or avoided according to the number of hours worked. Visiting a physician or CAM provider is time consuming in terms of such things as the time required to make the reservation and for travel, waiting and the consultation itself. Our results are consistent with those of a previous study that showed an inverse association between the number of hours worked and the number of physician visits ${ }^{20)}$.

With regard to OTC medication and dietary supplement use, given that most OTC medications are only available at pharmacies, whereas dietary supplements are available at supermarkets or over the Internet, longer working hours may act as a greater barrier to accessing OTC medication than dietary supplements. The results of this study show that workers choose to utilize health resources that require fewer hours as their number of hours worked per month increases. This may increase the risk of health problems for those working longer hours, with some studies suggesting the possibility of delays in the diagnosis of serious conditions owing to the masking by OTC medications of symptoms of severe disease ${ }^{21,22)}$. Further, misuse, adverse reactions and interactions relating to the use of OTC medication and dietary supplements have been reported $^{22-24)}$. We therefore consider it important to provide appropriate education on the safe and effective use of OTC medication and dietary supplements, in particular targeting workers who may be experiencing symptoms and taking OTC medication or dietary supplements rather than visiting a physician due to their long working hours ${ }^{25)}$.

Interestingly, participants who worked the longest hours made the most visits to emergency rooms. Although we did not determine the relative risk for emergency room visits due to the small size of the study population, long working hours may keep symptomatic employees from accessing appropriate health resources and result in more serious conditions that ultimately require emergency room visits. If correct, this may highlight that longer working hours can act as a barrier to accessing appropriate health resources, and may be a cause of concern to workers.

Even in the case of non-life-threatening symptoms such as migraine or fatigue, these conditions contribute to a loss of productivity ${ }^{26)}$ and a reduction in QOL that can lead to other more serious conditions such as depression ${ }^{27,28)}$. Longer working hours leading to reduced health resource utilization can therefore affect productivity and long-term health conditions. Future longitudinal studies are required to determine whether different patterns of health resource utilization relate to health risk, QOL and productivity in full-time workers.

\section{Association between hours worked and symptoms experienced}

We did not find any significant association between hours worked and the number of symptoms experienced. A number of reasons for this can be considered. First, we excluded people who worked less than $100 \mathrm{~h}$ per month on the basis that preexisting chronic health problems may have prevented them from working longer ${ }^{4}$. A previous study ${ }^{7)}$ reported a U-shaped association between hours worked and the risk of acute myocardial infarction, with the authors speculating that shorter working hours may indicate a premorbid condition, which therefore explains the association between shorter working hours and a higher risk of myocardial infarction. In our study population, people who worked less than $100 \mathrm{~h}$ per month had approximately twice the number of diseases currently being treated (mean 0.57, SD 0.76) and symptoms per month (mean 19.4, SD 14.6) than those who worked more than $100 \mathrm{~h}$. However, the number of diseases under treatment did not differ among the three groups who 
worked more than $100 \mathrm{~h}$ (chi-square test, data not shown). Quality of life score (PCS) at baseline also showed no difference among these groups.

In addition, the mean number of hours worked by the participants in our study was longer than that of Japanese workers in 2002 (9.88 vs. 7.16 h per day, respectively $)^{29)}$. The health conditions of the participants in our study may therefore not represent those of the broader Japanese working population as there may be a "healthy worker effect," with the participants in this study being in better health on average and therefore able to work longer hours. Second, as the aim of this study was to inquire into the comprehensive health status and pattern of health resource utilization among full-time male Japanese workers, we did not limit the symptoms for analysis. The possible healthy worker effect and variety of symptoms analyzed in our study are therefore likely to lead to conservative estimates of the associations found.

\section{Strengths and limitations}

One strength of this study was that health diaries provide immediate and continuous records of the daily symptoms and health resource utilization of participants, and therefore the risk of recall bias was minimized.

There were also several limitations to this study. First, although the demographic characteristics of the subjects were similar to those obtained in the Japanese national census, the participation rate in our study was low, and we therefore cannot rule out the possibility of selection bias. Second, we did not include several variables that may be risk factors affecting the health status of workers and health resource utilization, such as the number of hours slept, alcohol consumption, smoking status, and jobrelated stress. We assume that these factors may affect the more conservative results regarding the association between hours worked and health status or physician visits. However, given the small number of studies on the impact of these factors on health resource utilization, the implications of this study have to be considered carefully. Finally, given that the study duration was one month, we are unable to address the long-term influence of health resource utilization or health status on full-time male Japanese workers.

\section{Conclusion}

The findings in this study indicate that there are numerous associations between the number of hours worked and the type of health resource utilized by symptomatic workers. The results showed that the more hours worked, the more time constraints influenced the health resource utilization choices of workers. This suggests that the impact on industrial health may be substantial if long working hours keep symptomatic workers away from appropriate health resources and in turn result in a poorer health status. More attention should therefore be paid to the patterns of health resource utilization among workers and the influence of this on long-term health status. Companies should also encourage employees to reduce the number of hours worked and should help them secure access to appropriate health resources by allowing greater flexibility in working conditions.

Acknowlegments: This research was supported in part by grants from the St. Luke's Life Science Institute, Tokyo, Japan

\section{References}

1) The Ministry of Health, Labor and Welfare of Japan. Press Release 2008: Report of compensations associated with work-related brain, heart and psychological disorders. (in Japanese) [Online]. 2009 [cited 2009 Jun16]; Available from; URL: http://www.mhlw.go.jp/ houdou/2009/06/h0608-1.html

2) International labour Organization Department of Statistics. International Labour Office database on labour statistics. [Online]. [cited 2011 Jan 20];Available from; URL: http://laborsta.ilo.org/data_topic_E.html

3) Suwazono Y, Sakata K, Harada H, et al. Benchmark dose of working hours in relation to subjective fatigue symptoms in Japanese male workers. Ann Epidemiol 2006; 16: 726-32.

4) Yang H, Schnall PL, Jauregui M, Su TC, Baker D. Work hours and self-reported hypertension among working people in California. Hypertension 2006; 48: 744-50.

5) Nakanishi N, Yoshida H, Nagano K, Kawashimo H, Nakamura K, Tatara K. Long working hours and risk for hypertension in Japanese male white collar workers. J Epidemiol Community Health 2001; 55: 316-22.

6) Kawakami N, Araki S, Takatsuka N, Shimizu H, Ishibashi H. Overtime, psychosocial working conditions, and occurrence of non-insulin dependent diabetes mellitus in Japanese men. J Epidemiol Community Health 1999; 53: 359-63.

7) Sokejima S, Kagamimori S. Working hours as a risk factor for acute myocardial infarction in Japan: casecontrol study. BMJ 1998; 317: 775-80.

8) Guo HR. Working hours spent on repeated activities and prevalence of back pain. Occup Environ Med 2002; 59: 680-8.

9) Virtanen M, Singh-Manoux A, Ferrie JE, et al. Long working hours and cognitive function: the Whitehall II Study. Am J Epidemiol 2009; 169: 596-605.

10) Kleppa E, Sanne B, Tell GS. Working overtime is associated with anxiety and depression: the Hordaland Health Study. J Occup Environ Med 2008; 50: 65866.

11) van der Hulst M. Long workhours and health. Scand J Work Environ Health 2003; 29: 171-88.

12) Harma M. Are long workhours a health risk? Scand J Work Environ Health 2003; 29: 167-9.

13) Artazcoz L, Cortes I, Borrell C, Escriba-Aguir V, Cascant L. Gender perspective in the analysis of the 
relationship between long workhours, health and healthrelated behavior. Scand J Work Environ Health 2007; 33: $344-50$.

14) Nylen L, Voss M, Floderus B. Mortality among women and men relative to unemployment, part time work, overtime work, and extra work: a study based on data from the Swedish twin registry. Occup Environ Med 2001; 58: 52-7.

15) Nishiyama K, Johnson JV. Karoshi-death from overwork: occupational health consequences of Japanese production management. Int J Health Serv 1997; 27: 625-41.

16) Spurgeon A, Harrington JM, Cooper CL. Health and safety problems associated with long working hours: a review of the current position. Occup Environ Med 1997; 54: 367-75.

17) Fukui $T$, Rhaman M, Takahashi O, et al. The ecology of medical care in Japan. JMAJ 2005; 48: 163-7.

18) Fukuhara S, Suzukamo Y. Manual of the SF-8 Japanese version. Kyoto: Institute for Health Outcomes and Process Evaluation Research; 2004. p. 27-33.

19) Dobson J Annette. An introduction to generalized linear models. 2nd ed. Boca Raten, FL: Chapman \& Hall/CRC; 2002.

20) Fell DB, Kephart G, Curtis LJ, et al. The relationship between work hours and utilization of general practitioners in four Canadian provinces. Health Serv Res 2007; 42: 1483-98.

21) Sheen CL, Colin-Jones DG. Review article: over-thecounter drugs and the gastrointestinal tract. Aliment
Pharmacol Ther 2001; 15: 1263-70.

22) Hammerlein A, Griese N, Schulz M. Survey of drugrelated problems identified by community pharmacies. Ann Pharmacother 2007; 41: 1825-32.

23) Timbo BB, Ross MP, McCarthy PV, Lin CT. Dietary supplements in a national survey: prevalence of use and reports of adverse events. J Am Diet Assoc 2006; 106: 1966-74.

24) Dennehy CE, Tsourounis C, Horn AJ. Dietary supplement-related adverse events reported to the California Poison Control System. Am J Health Syst Pharm 2005; 62: 1476-82.

25) Bradley CP, Bond C. Increasing the number of drugs available over the counter: arguments for and against. Br J Gen Pract 1995; 45: 553-6.

26) Munakata J, Hazard E, Serrano D, et al. Economic burden of transformed migraine: results from the American Migraine Prevalence and Prevention (AMPP) Study. Headache 2009; 49: 498-508.

27) Hamelsky SW, Lipton RB. Psychiatric comorbidity of migraine. Headache 2006; 46: 1327-33.

28) Lipton RB, Hamelsky SW, Kolodner KB, Steiner TJ, Stewart WF. Migraine, quality of life, and depression: a population-based case-control study. Neurology 2000; 55: 629-35.

29) The Ministry of Internal Affairs and Communications. Report of Survey of Time Use and Leisure Activities 2002 (in Japanese). [Online]. [cited 2011 Jan 18]; Available from: URL: http://www.stat.go.jp/data/ shakai/2001/index.htm 